\title{
Feminist and Queer Approaches to Education for Spatial Citizenship
}

\author{
Noemi De Luca ${ }^{1}$, Nicole Ferber ${ }^{2}$, Helena Atteneder ${ }^{2}$ and Thomas Jekel ${ }^{3}$ \\ ${ }^{1}$ CESIE, Palermo/Italy·noemi.deluca@cesie.org \\ ${ }^{2}$ Department of Geoinformatics - Z GIS, Salzburg University, Austria \\ ${ }^{3}$ Department of Geography and Geology, Salzburg University, Austria
}

Full paper double blind review

\begin{abstract}
This contribution suggests that Feminist and Queer Studies, and more explicitly Feminist and Queer cartographies, may contribute widely to an education for Spatial Citizenship, aiming at participation and empowerment. Based on basic competence dimensions of Spatial Citizenship education, the paper explores existing theoretical and empirical work for technical and methodological skills, reflexive geo-media use, and practices of communication and participation. The evidence is systematized in order to suggest a Research Agenda, as well as to provide an overview of educational approaches that may be readily translated to secondary school use.
\end{abstract}

\section{Introduction}

The concept of Education for Spatial Citizenship was originally developed as an alternative argument to the then dominant discourse of technical and spatial thinking arguments (NRC 2006) for the inclusion of geoinformation in secondary education (JEKEL et al. 2010, GRYL \& JEKEL 2012, DE LuCA et al. 2014, JEKEL et al. forthcoming). Spatial Citizenship is reasoned by the role lay users of geomedia may or may not play in the everyday appropriation of space, and therefore are rooted in the emancipatory domain of education.

According to the original model of Spatial Citizenship, a spatial citizen that is able to participate in society should be able to interpret and critically reflect on spatial information, communicate with the assistance of maps and other spatial representations, and express location-specific opinions using geomedia (JEKEL et al, forthcoming). These abilities are deemed necessary to actively engage in the transformation of the world we live in, rather than merely in its description and analysis. With the aim of providing citizens with the necessary skills, attitudes, and knowledge to pursue their active participation, the authors of the concept heavily relied on a competence model developed on the basis of interdisciplinary education models, including political education, and transferred it to geomedia education (KRAMMER et al. 2008, GRYL \& JEKEL 2012). The original model included the following core dimensions (JEKEL et al., forthcoming): Technology and methodology to handle geomedia (see also STROBL 2008, 136); Reflection and reflexivity regarding geomedia (an extension of classical consumption skills of map reading through deconstruction, conscious hypotheses production and envisioning space); Communication, participation and negotiation with geomedia (competences for active communication and participation 
strategies). As a participation-oriented approach, Education for Spatial Citizenship aims to support all strata of society, by engaging all individuals in participatory processes that lead to the re-signification and appropriation of space. However, research has not yet dealt with the potential of education for Spatial Citizenship to, a) encourage an inclusive understanding of identity, and hence of the citizen; b) acquire a gender perspective inspired by the Feminist and Queer approaches; c) foster different and individualized approaches to geomedia education to promote equal geomedia use; d) provide the skills for the exploitation of the power of geomedia to support fluid power relations in society. Furthermore, no effort is visible so far to include knowledge gained from gendered and queer approaches in cartography and GIScience for education in the field.

Empirical research so far has focused on the technical aspect of contributing volunteered geographic information. HAKLEY \& BUTHADOKI (2010) refer to results indicating that OpenStreetMap data is contributed to a minimal extent by females, i.e. $3 \%$. These results are echoed by STEINMANN et al. (2013), who explored motivational factors of contributions of VGI. STEPHENS \& RONDINONE (2012) suggest that women are volunteering nongeographic social information on the Internet, but are not intentionally volunteering geographic information even within a social context. They conclude that "men are the primary constructors of the world view that is represented by VGI". Not willing, or not being able to contribute would therefore lead to the explicit exclusion from decision-making processes.

While some empirical research exists in the technical component of contributing geographic information, the other dimensions of education for Spatial Citizenship (reflection/reflexivity, participation, and decision making) have very little known research in the area denoted by Feminist or Gender approaches, the geoweb, and education.

This paper therefore explores possible links between these fields, with the explicit aim of adopting a gender approach in an education for Spatial Citizenship. It does so by going beyond the geomedia domain, and heavily draws on work done in more general Communication Science, Feminist, and Queer pedagogies to return new insights to geomedia-based education.

\section{Gender: A Relational Concept in Feminist \& Queer Theories}

As it is argued in the following sections, the conceptual link between Feminist/Queer Theories and the education for Spatial Citizenship (and even more in general with GIS) has not yet been explored. It is therefore necessary to demonstrate, as a first step, how the concepts of relational identity and performance of gender relate to and overlap with the Spatial Citizenship concepts of reflection, reflexivity, communication, participation, and negotiation of spaces. The understanding of gender identity can, in fact, inform the education for Spatial Citizenship, as it promotes a more inclusive understanding of citizenship and of participation. Historically, many categories of individuals have been excluded from decision-making processes. Women especially have played a minor decision-making role in nearly all cultures, with few exceptions. The bias of the patriarchal society was exposed mainly by Simone de Beauvoir, a French philosopher and main representative of Second-Wave Feminism, by opposing to the idea that women were inherently inferior to men, and by focusing on the process of becoming a woman instead (DE BEAUVOIR 1949).

Gender roles, as coined by sexologist John Money, are crucial in analyzing the contribution of Queer theory in the more recent understanding of gender identity (MONEY \& ANKE 
1972). Gender roles - i.e. the implicit set of behaviors prescribed for women and for men by culture and by the society - expose the essence of binary gender identity (woman/man), which results in fixed gendered rights based on such dichotomy. The individuals who do not conform to the gender roles assigned to them (implicitly and explicitly) are ostracized as different, and excluded from mainstream society. The discourse hence goes beyond the mere inequality between "the second sex" (DE BEAUVOIR 1949) or the "other sex" (IRIGARAY 1995) and the "one" individual - man (IRIGARAY 1995). A more complex and thorough understanding of gender was brought forward by Queer theory, which introduced the deconstruction of gender into several layers of identity, with the political implications that follow. But what is Queer theory and what can its contribution be to Spatial Citizenship?

Despite the recent improvements of gender equality in some countries, the mainstream understanding of gender still represents a barrier for the full and equal participation of all individuals in society. In this sense, first Feminism, and later Queer theory, produced a rupture in the normative understanding of gender. As Feminism recognized and rejected the understanding of woman as defined in relation to man, it also reinforced the acknowledgment of two separate gender identities only: woman and man, respectively corresponding to the female and to the male sex. The merit of Queer theory was to reintroduce the relational character of gender identity and to deconstruct gender as fully unrelated to the biological sex and consisting of a collection of behaviors repeated in time, thereby turning gender into a fluid category, a continuum where woman and man are only two extremes of the same spectrum, with possibilities for self-expression and external influence in between. Therefore, each individual has their unique gender identity, and each one of us is shaped by and shapes the world that we live in. Contexts, situations, cultural background, etc. play a role in determining our gender identity, and at the same time we analyze the world through the lenses of our identities (in line with the concepts of reflection and reflexivity of Spatial Citizenship). Such a concept of gender identity helps uncover a link between Queer theory and education for Spatial Citizenship, in the sense that the deconstruction of gender can lead to the deconstruction of mainstream understandings of citizenship, with an outlook to an open category allowing the inclusive participation in the society. All individuals are therefore acknowledged as playing an active role in shaping the society, including appropriating the space by attaching new meaning to it, communicating with others and negotiating for alternative understandings and usages of space. The underlying concepts of Spatial Citizenship thus overlap with the concepts of constructing and deconstructing contexts and behaviors as in the theory of performativity of gender, introduced by the main philosopher of Queer theory, Judith Butler, together with the concept of performance of gender. Performance is related to the (self-)representation of one's gender; it includes the behaviors that individuals adopt, either consciously or unconsciously, and the way these are perceived by themselves and by the society as corresponding to or deviating from traditional gender roles. The concept of performativity relates to the discourse around the representation of gender (BUTLER 1990). If we consider gender as performance, we allow the necessary logical space for the existence and appreciation of all the identities, which would not necessarily be represented in the gender binary system, rejecting a natural character of the male/female opposition, which simply does not serve the purpose of understanding the infinite differences in gendered behavior that exist in real life (BUTLER 1990, BUTLER 2004).

Gender becomes a multi-layered concept that is made up of biological and especially of cultural components. Not only does gender assume different connotations depending on each individual, but it is also largely dependent on the context and on the behavior of indi- 
viduals. The agency of people is hence recognized and underpinned by the relational character of gender, and thus ultimately of identity. Adopting a fluid perception of gender is key to a more inclusive society, where all individuals are empowered and inspired to be active citizens and share their views and rights with others, regardless of their gender identity. More inclusive concepts of gender identity can in fact be beneficial for, and contribute to, a more participative appropriation of space, rather than the traditional restriction of space (physical and mental) for "deviant identities" that was denounced already in 1993 by Eve Kosofosky Sedgwick through the use of the metaphor of the closet (SEDGWICK 1993). As the mainstream understanding of gender identity remains in use, it is helpful to deconstruct and analyze gender, and to adopt a gender perspective in the framework of citizenship and participation.

Gender works as a social construct, alongside other social categories. Spatial Citizenship should then be integrated with not only a gender approach, but ultimately with an understanding of plural identities that is central in the concept of intersectionality - meaning the co-existence and juxtaposition of (social) categories that may cause inequalities. Social categories are often compounded or intersected by inequalities based on class, race, ethnicity, or age. The concept of intersectionality is consistent with the assumed "plurality of identities" within the Cultural Studies, and is historically rooted in "Black Feminism", which combines the fight against racial and gender discrimination. (WINKER \& DEGELE 2010, $11 \mathrm{f}$.) However, the concept of intersectionality still remains largely underrepresented in mainstream (empirical) studies, which could be explained by a gap in knowledge of methodical and empirical design of studies. The interdependence of different categories provokes theoretical and methodological barriers. Nevertheless, the fact that discrimination is not just based on one layer of inequality makes the concept of intersectionality not just a promising, but also an essential tool to consider in further studies, as it complements the analysis of gender roles and gender identity, allowing the analysis of inequality and relational identity from a multitude of perspectives. As the performativity of gender holds the potential to disrupt and resignify social norms, adopting a gender perspective (and even more so, an intersectional perspective) can represent a new viewpoint in the concept of appropriation of space and negotiation of social norms embedded in space that are the key themes to the education for Spatial Citizenship.

\section{Gender Media Studies \& the (De)Construction of Citizenship}

As mentioned above, the meaning of being a citizen has changed over decades but it has always been linked to participation (of those who were citizens) and drew the borders of social inclusion and exclusion.

Several developments have led to a need for rethinking citizenship, which was largely taken for granted since the Age of Enlightenment and the bourgeois revolutions in Europe. Globalization and the rise of multi-ethnic, multi-cultural societies and migration processes, as well as the development of popular media discourses driven by the rise of new digital media, have put the concept and clear meaning of citizenship into question (BENNET et al. 2009). Referring to these developments, the meanings of citizenship and of citizen participating in society can include different concepts. However, a common ground exists: Citizenship relates to cultural identity and cultural practices and participation. It therefore poses questions for social inclusion and exclusion. Different scholars loosely name these aspects 
cultural citizenship (KLAUS \& LÜNENBORG 2012, 197 f.). Klaus \& Lünenborg proposed a mediated meaning of cultural citizenship. As media dominates our modern society, and forms of online communication blur the classical roles of media production and of media consumption (reception), participation is made possible across national and cultural boundaries. In accordance with this understanding of the modern role of media, KLAUS \& LÜNENBORG (2012) define the concept of cultural citizenship as follows: "Cultural citizenship is an essential dimension of citizenship in media society and unfolds under the conditions of unequal power relations. It entails all those cultural practices that allow competent participation in society and includes the rights to be represented and to speak actively. Media as particular form of cultural production is both an engine and an actor in the process of self-making and being-made, in which people acquire their individual, groupspecific and social identities. " (KLAUS \& LÜNENBORG 2012, 204)

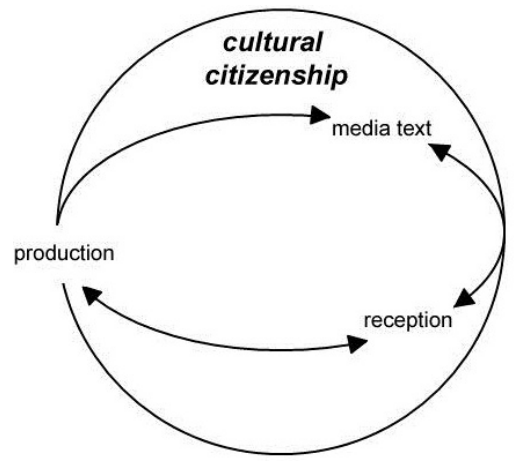

Fig. 1 Cultural Citizenship as part of the circuit of culture (own illustration adapted from KLAUS \& LÜNENBORG 2012, 205).

In media societies, media play an important role for the participation of citizens. Spatial Citizenship and the requested abilities that lead to active participation and empowerment can be seen as subparts of cultural citizenship.

This paper refers to two potentially strong dimensions for change: media and education. Media not only reflect economic interests in a neoliberal media system, but may lead to changing stereotypes and give voice to members of discriminated groups. Connected with education and empowerment of a young generation, change may be possible from a grass-roots level. In accordance with the concept of gender roles, gender media studies then research the role media plays in the construction of social reality, and also provide methods for deconstruction of gender roles through media.

For the analysis of the construction of gender roles, SOTIROVIC (2008) identifies gender and age differences in news media use and the influence on political knowledge. Relating to a generational use of media, it can be said that electronic media are more frequently used among the younger generations; however, gender gaps in media use exist among all generations. Gender-specific media use leads to a gender gap in political knowledge, i.e. lower knowledge among women.

VAN DEN BULCK \& VAN DEN BERGH (2000) show gender differences in the parental guidance of media consumption among 10 to 11 year olds. Already at this early age, it is observed that the media use of boys and girls differs. In general, boys are playing more computer games and girls are reading more books. The parental guidance of media consumption plays an important role in media behavior. But not only have the parents influenced their children's attitude, but also children exercise an influence over the attitude of their parents. The authors point out, that in developmental psychology, socialization is seen as a bidirectional process. Different types of media seem to offer different gratifications for the children. In case of a parental restriction on media use, children switch to different media that offer similar gratifications to them. Boys and girls seem to have "learned" or have been socialized to choosing different types of media. 
COTTON et al. (2014) highlight the need for a link between gender and technology ownership and use (multitasking). In a study among middle school students, they concluded that more boys owned and used gaming systems, whereas more girls owned and used cell phones and MP3 players. Girls and boys evenly engage in general technology multitasking (chatting, emailing, listening to music, etc.), and the ownership of an increasing number of technology platforms led to a prevalence of multitasking excluding gaming. According to previous findings on this topic, the authors identify a greater use of communicative technologies by females, and greater use of gaming technologies by males. Closer to secondary education, RATTENSBERGER et al. (2005) analyzed geography textbooks, to demonstrate the construction of rather traditional gender roles despite political declarations to the contrary.

In summary, it can be noted that gender is reproduced through both media content and media consumption. Gender media studies follow three general steps (KLAUS \& LÜNENBORG 2012): support of equalization of gender roles, a differential approach pointing out and accepting differences between genders, and deconstruction of the gender roles "transported" and reiterated by media. It may be argued that the academic debates on learning with Geomedia in general, and Spatial Citizenship in particular, so far have little to offer in terms of supporting the above aims. The first goal for contribution by Spatial Citizenship may in this sense derive from these studies in the form of techniques for deconstructing social reality for reflexive media use.

\section{$4 \quad$ Feminist and Queer Cartographies/GIS}

The connection of Feminist theories and cartographies/geographic information systems (GIS) were brought forward mainly through the work of critical (GIS) scholars (KwAN 2002). Those scholars, who were interested in non-positivist practices of knowledge production, considered the sensitive use of gender and other power hierarchies that produce social economic and cultural differences as an important issue in their work. Feminist GIS led the way to a more critical engagement of social theory with GIS. The critical engagement began with critiques on knowledge production first in science, geography, and cartography, and just recently of information and communication technologies (PAVLOVSKAYA \& MARTIN 2007). In the historical realm of knowledge production in cartography, women have played a marginal role. Most histories deny the "presence of women as either subjects or objects of mapping technologies" (PAVLOVSKAYA \& MARTIN 2007, see also DUNCAN \& LEY 1994). Women began to play a role only with the second wave of Feminism in the last quarter of the $20^{\text {th }}$ century, when male-dominated fields of employment opened up for them. Cartographic knowledge and map authoring were closed to women since they were excluded from the technical education altogether. Nevertheless, the way women were influential was in modern map production and printing, as well as in the distribution and interpretation of map products, especially as educators. Other instances of influence were only possible through travel writings and as shadow partners of husbands and fathers in cartography-related businesses. Today, the male dominance mainly in top positions in GIS and related fields is still an undeniable fact. A growing number of women are employed in the creation and correction of digital spatial information. The second influential point of Feminist theory on cartography is the actual mapping of women and their view of the world. The Feminist or Queer cartographies/GIS approaches brought a deeper insight to gendered spaces (PAVLOVSKAYA \& MARTIN 2007). 
However, the most influential critique from Feminist theory on cartography and GIS stems from the review of visual practices and representations, and the influence of mainstream methods of science, vision, cartography, and GIS. Feminist theorizations center their argument on the fact that mainstream practice of Western science is based on observation. According to the dominant strategy of science, research is currently based on vision, and the observer is seen as uninvolved, pretending to maintain distance from the observed subject. The social context of observations and the relation to the observed is completely ignored. Those that do not fit the picture of western mainstream science, such as disabled people, the elderly, children, sexual minorities, women, and colonial subjects, are seen as the embodied and situated subjects who are not entitled to make claims about the absolute truth, power and authority (PAVLOVSKAYA \& MARTIN 2007). Feminists criticize that this understanding of science and of the scientist serves those in power and supports the status quo.

\section{$5 \quad$ Feminist \& Queer Pedagogies}

Feminist pedagogies have been closely related to Paulo Freire's critical pedagogy for much of the academic discussion. Differently than some of the empirical work cited at the beginning of this contribution, Feminist pedagogy aims at empowerment, autonomy, and mutuality (SHREWSBURY 1993) that may be seen as pivotal objectives of education for Spatial Citizenship as well. Reflection and communication feature highly, enabling several links to the basic dimensions of Spatial Citizenship. It therefore pays to explore basics and methods of Feminist and Queer pedagogies in some greater detail.

"At the core of feminist pedagogies is a re-imagining of the classroom as a community of learners where there is both autonomy of self and mutuality with others that is congruent with the developmental needs of both women and men" (SHREWSBURY 1993, 12). While Shrewsbury here clearly addresses shortcomings of pedagogies of the time (and probably, current), this definition still seems to be rooted in binary constructions of gender and identity. As a result, the close to infinite perspectives of a widened relational approach to gender are still missing, therefore hindering the resourceful adoption of teaching methods that could act as an important vehicle of gender-sensible pedagogy, as FORTUYN $(2011,176)$ notes:

"Feminist pedagogy is characterized by a non-hierarchical relationship between student and teacher. Students are stimulated to actively take part, to bring their personal experiences into the classroom and to relate these experiences with theoretical knowledge, and are therefore seen as individuals with specific expertise”.

Considering the basic concept of SPACIT, there is convergence in a general relational thinking, as denoted in the conceptions of mutuality and non-hierarchical relationships within the classroom, as well as in the aim for autonomy and empowerment of the subject. While these conceptions are true for a whole lot of constructivist pedagogies in the field of geomedia education (GRYL et al. 2014), they clearly argue for respect for differing developmental needs, albeit in a binary way. The integration of the approach of Queer theory would compensate and contribute with a more inclusive, differentiating, and individualizing aspect in education.

Nevertheless, linkups between gender and queer pedagogies and spatialized media are still missing. Pedagogical approaches that are centered on identity construction, but do not include the spatial dimensions of this construction of identity, may well be considered poor 
on several accounts, namely missing out on the experience of the learner, that is inherently spatial, and overlooking the importance of the gendered and male-dominated domain of spatial representation. A queered education for Spatial Citizenship should explicitly focus on these dimensions.

\section{Feminist/Queer GIS \& Education for Spatial Citizenship}

Thanks to the availability of spatially-enabled mobile devices and online interactive mapping platforms such as Google Maps, as well as social media outlets for data publishing, geomedia augments every aspect of our daily life. These new technologies had a fundamental influence on knowledge production since 'volunteered geographic information (VGI)': "digital spatial data (...) are produced not by individuals and institutions formally charged as data producers, but rather, are created by citizens who use the tools described (...) to gather and disseminate their observations and geographic knowledge" (ELWOOD 2008). The current discussions on neogeography emphasize that the usage and production of geographical information has been fundamentally democratized over the last couple of years. Democratization in the context of neogeography is to be considered in the interaction of people and technology, and is, as stated by HAKLAY (2013), "in a more colloquial notion (...) making a process or activity that used to be restricted to an elite or privileged group available to a wider group in society and potentially to all". The notion of democratization in terms of the potential of neogeography is argued as the "ability to assemble, organise and share geographical information to anyone, anywhere, and anytime" (HAKLAY 2013). But democratization has also "a deeper meaning in respect of making geographic information technologies more accessible to hitherto excluded or marginalized groups in a way that assists them to make changes in their life and environment" (HAKLAY 2013). Even if the participation and contributions of volunteered geographical information is growing, the number of people actively involved in generating user-generated content (UGC) is limited so far. Research on the exploring factors, which influence this phenomenon of relatively lower participation rates especially in VGI projects, is still missing (STEINMANN et al. 2013). Exclusion factors are expressed in "epistemologies, vocabularies, and categories of data structures (that) do not or cannot encompass the experiences, knowledge claims, and identities of some of the social groups or places" (ELWOOD 2008).

LESZCZYNSKI \& ELWOOD (2014) argue that new spatial media "designate both the technological devices and the information artifacts, that result from the intensifying convergence of digital information communication technologies (ICT) with location and emergent spatial information technologies, (re)produce gender(ed) identities, norms, subjectivities, exclusions, and space in new, unprecedented ways".

Their empirical study on Feminist geographies of new spatial media presents three key dimensions in terms of everyday use of new spatial media. The first dimension (LESZCZYNSKI \& ELWOOD 2014), takes into account the new practices of data creation and curation, which is still a field influenced by patriarchic patterns. Since men are the main contributors to VGI projects like OpenStreetMap (OSM), they are more likely to influence what is going to be included. This aspect is addressed in the SPACIT dimensions as communication, participation, and negotiation (with geomedia). The second dimension the authors point out is to understand the gender division due to the affordances of new technologies, which implies the power of those who are designing, engineering, programming and doing the software 
development. Affordance is here meant as the perceived functional capabilities of technologies and as what the features or functional capabilities of technologies can be used for. Those who dominate technological domains also dominate the values encoded into and conveyed through technologies. One example is the design and conceptualization of apps that mine social media data such as Foursquare check-ins of women, to calculate the density of women in specific places in order to target female hot spots. This dimension goes hand in hand with the SPACIT dimensions on technology and methodology competences. The third dimension (LESZCZYNSKI \& ELWOOD 2014) is the influence on new digital spatial mediations of everyday life, which imply the way in which media technologies increasingly broker and disrupt our everyday experiences. It implies the pressure of being connected, but also to protect your personal data. Not only does the different degree of spatial vulnerability between men and women in wired societies matter; those technologies also structure opportunities in life, e.g. the access to (digital) networks increases employability. Reflection and reflexivity (regarding geomedia) play a key role in new digital mediations of everyday life and also connect with one of the SPACIT key dimensions for an Education for Spatial Citizenship.

The intersections of feminist GIS with the concept of Spatial Citizenship is seen in connection with the ability of a spatial citizen to participate in society, in terms of the interpretation and critical reflection on spatial information, the communication with the assistance of spatial representations, and the expression of location-specific opinions using geomedia (JEKEL et al, forthcoming).

A way forward from a feminist point of view and in the terms of Spatial Citizenship is, on the one hand, the integration of the concept of intersectionality, as defined above. On the other hand, as Donna Haraway (HARAwAY 1988, KoBAYASHI 2009, PAVLOVSKAYA \& MARTIN 2007) states, knowledge production can be addressed with the concept of "situated knowledge" as an alternative epistemology of science. The premise of the concept is that all knowledge is localized, partial, and embodied, and cannot be claimed as absolute truth. This knowledge could be seen as diversification and enrichment of the (scientific) world. Situated knowledge is reviewed following two major perspectives, one focusing on reflexivity as "the understanding of the geographical self in relation to others; the other perspective "focusing on the construction of the other through geographical imaginations" (KoBAYASHI 2009, 138).

\section{Towards a R\&D Agenda}

How could we address the different approaches to spatialities and ICT in terms of gender/minorities and the digital divide within an ICT-centered society? From the above insights of both Feminist/Queer theory and Spatial Citizenship, it seems to be essential to take a closer look at how to support the students/teacher to better understand gender aspects in relation to different fields. Necessary research areas include, but are not limited to:

1. Deconstruction of gender roles with/within (geo)media presumption \& pedagogical strategies. Here, research should concentrate on the motivation of role-specific uses to address and to provide a basis for a more inclusive approach to geomedia education, aiming to equal participation. Gender- sensible strategies of teaching need to be developed based on existing and future analysis of motivational structures. 
2. The approach of (geo)media in terms of intersectionality to deconstruct and express inequalities with/of (geo)media. This research area allows for a spatial approach in terms of hypothesis generation, as well as for inequalities within geomedia and the world view it transports. Both areas need to be addressed in secondary education.

3. A fluid perception/comprehension of (geo)media prosumption i.e. different intentions, identities, inequalities. One of the main aims is the development of mutual competences of reading gender-/role-specific geomedia, i.e. pedagogical strategies have to be developed that allow the 'others' to interpret geomedia as an expression of different intensions, identities, and inequalities.

4. Envision and reflect the relational aspects of gender, identity and space. Little research currently is available that links 'traditional' gender/queer studies' sensibilities for relational aspects with both space and pedagogy. Further research is needed for practical implementation at school level.

5. The approach of situated knowledge in terms of knowledge production with (geo)media. (Geo)media prosumption is to be reviewed as localized, partial and embodied.

\section{References}

BennetT, W. L., Wells, C. \& RANK, A. (2009), Young citizens and civic learning: two paradigms of citizenship in the digital age. Citizenship Studies, 13/2, 105-120.

Butler, J. (1990), Gender Trouble: Feminism and the Subversion of Identity. Routledge, New York/London.

ButLer, J. (2004), Undoing Gender. Routledge, New York/London.

Cotton, S. R., Shank D. B. \& Anderson, W. A. (2014), Gender technology use and ownership, and media-based multitasking among middle school students. Computers in Human Behavior, 35, 99-106.

De Beauvoir, S. (1949), Le deuxième sexe. Gallimard, Paris.

De LuCA, N., Ferber, N. \& JeKel, T. (2014), Spatial Citizenship Education - Empowering Citizens with Geomedia. Conference Proceedings 8th INTED Conference, Valencia, Spain, 1618-1627.

DunCAN, J. \& LEY, D. (1994), Introduction: Representing the Place of Culture. In: DunCAN, J. \& LEY, D. (Eds.), Place/Culture/Representation. London/New York, 1-21.

ELWOOD, S. (2008), Volunteered geographic information: future research directions motivated by critical, participatory, and feminist GIS. GeoJournal, 72, 173-183.

FORTUYN, J. D. (2011), Teaching gender and geography: the case of the Netherlands, International Research in Geographical and Environmental Education, 20 (3), 175-178. DOI: 10.1080/10382046.2011.588492.

GRYL, I. \& JEKEL, T. (2012), Re-centering GI in secondary education. Towards a spatial citizenship approach. In: Cartographica, 47 (1), 18-28.

Gryl, I., SAnchez, E., JeKel, T., Jouneau-Sion, C., Lyon, J. \& Höhnle, S. (2014), Educational Uses of Geomedia. In: JeKel, T., SANChEZ, E., GrYL, I., JounEAu-SiOn, C. \& LYON, J. (Eds), Learning and Teaching with Geomedia. Cambridge Scholars, Newcastle upon Tyrne.

HAKLAY, M. (2013), Neogeography and the delusion of democratisation. Environment and Planning A, 45, 55-69. 
HARAwAY, D. (1988), Situated Knowledges: The Science Question in Feminism and the Privilege of Partial Perspective. Feminist Studies, 14, 575-599.

IRIGARAY, L. (1995), The Question of the Other. Yale French Studies. Another Look, Another Woman, 87.

Jekel, T., Gryl, I. \& Donert, K. (2010), Spatial Citizenship. Beiträge von Geoinformation zu einer mündigen Raumaneignung. Geographie und Schule, 32, 186, 39-45.

JEKel, T., GrYl, I. \& SCHUlze, U. (forthcoming), Education for Spatial citizenship. In: Muniz-Solari, O, Demirci, A. \& VAn Der Schee, J. (Eds.), Geospatial Technologies and Geography education in a changing world. Springer, Tokyo.

Klaus, E. \& LÜnenborg, M. (2012), Cultural Citizenship. Participation by and through Media. In: Zobl, E. \& DrÜEKe, R. (Eds.), Feminist Media, Participatory Spaces, Networks and Cultural Citizenship. Transcript, Bielefeld, 197-212.

KWAN, Mei-Po (2002), Is GIS for Women? Reflections on the critical discourse in the 1990s. Gender, Place \& Culture, 9 (3), 271-279.

KobAyASHI, A. (2009), Situated Knowledge, Reflexivity. In International Encyclopedia of Human Geography, ed. by R. K. Thrift. Elsevier, Oxford, 138-143.

KRAMMER, R. et al (2008), Die in politischer Bildung zu erwerbenden Kompetenzen. Ein Kompetenzstrukturmodell (Projektbericht für das BMUKK). Wien.

LESZCZYNSKI, A. \& ElWOOD, S. (2014), Feminist geographies of new spatial media. Les géographies féministes des nouveaux médias spatiaux. The Canadian Geographer/Le Géographe canadien, n/a-n/a.

Money, J. \& EHrhardT, A. (1972), Man and Woman, Boy and Girl: Gender Identity from Conception to Maturity. John Hopkins University Press, Baltimore.

Pavlovskaya, M. \& Martin, K. S. (2007), Feminism and Geographic Information Systems: From a Missing Object to a Mapping Subject. Geography Compass, 1, 583-606.

RATtensberger, M., BACHLEITNER, S. \& JeKel, T. (2006), Man(n) glaubt es kaum - Frau braucht Zeit und Raum. Eine Schulbuchanalyse. GW-Unterricht, 102, 17-26.

SedGwick, E. K. (1993), Epistemology of the Closet. In: Abelove, H., BARAle, M. A. \& HALPERIN, D. M. (Eds.), The Lesbian and Gay Studies Reader. Routledge, London/New York.

Shrewsbury, C. M. (1993), What is Feminist Pedagogy? Women's Studies Quarterly, 21 (3\&4), 8-15

Sotirovic, M. (2008), Gender Differences In News Media Use And Their Political Implications. Conference Papers - International Communication Association, 1-21.

Steinmann, R., HÄusler, E., Klettner, S., Schmidt, M. \& Lin, Y. (2013), Gender Dimensions in UGC and VGI: A Desk-Based Study. In: Jekel, T., CAR, A., Strobl, J. \& GRIESEBNER, G. (Eds), GI_Forum 2013. Verlag der Österreichischen Akademie der Wissenschaften, Wien, 355-364.

Stephens, M. \& RondinOne A. (2012), Gendering the GeoWeb, presentation at annual meeting 24-28.02.2012, New York. http://www.scoop.it/t/opensourcegeo/p/1452578643/gendering-the-geoweb-analysingdemographic-difference-in-usvgi.

VAN DEN BUlCK, J. \& VAN DEN BERGH, B. (2000), The Influence of Perceived Parental Guidance Patterns on Children's Media Use: Gender Differences and Media Displacement. Journal Of Broadcasting \& Electronic Media, 44 (3), 329.

WinKer, G. \& DegEle, N. (2010), Intersektionalität. Zur Analyse sozialer Ungleichheiten. Transcript, Bielefeld. 